\title{
Plasma catecholamine responses in acute severe asthma
}

T. R. J. PARKE*, D. J. STEEDMAN*, C. E. ROBERTSON*, R. A. LITTLE ${ }^{\dagger}$ \& P. F. MAYCOCK *Department of Accident and Emergency Medicine, Royal Infirmary, Lauriston Place, Edinburgh and ${ }^{+}$North Western Injury Research Centre, Stopford Building, Oxford Road Manchester

\section{SUMMARY}

Twenty patients presenting to an A\&E department with acute severe asthma were studied. Despite clinically severe airway obstruction few had raised catecholamine levels. However several patients with impending respiratory arrest had markedly elevated catecholamine levels, and relationships are demonstrated between these levels and other measures of disease severity.

\section{INTRODUCTION}

Catecholamine release occurs in response to physiological stress states such as hypotension, hypoxia, exercise and fear. Circulating adrenaline is primarily released from the adrenal medulla, whereas circulating noradrenaline is primarily derived from sympathetic nerve synapse overspill. High levels of both plasma adrenaline and noradrenaline have been recorded in life-threatening illness such as acute myocardial infarction, major trauma and cardiac arrest (Fig. 1) (Little et al., 1985).

It would be surprising, therefore, if catecholamine levels did not rise in patients with acute severe asthma. However, previous workers have suggested that asthmatics have a modified catecholamine response to various physiological stresses, such as exercise and allergen challenge (Warren et al., 1982; Carson et al., 1985). In addition, it has been shown that adrenaline levels do not rise in acute asthma though noradrenaline levels may be elevated (Ind et al., 1985). Speculation from such studies has resulted in the concept of a blunted sympatho-adrenal response

Correspondence: C. E. Robertson, Department of Accident and Emergency Medicine, Royal Infirmary, Lauriston Place, Edinburgh EH3 9YW. 

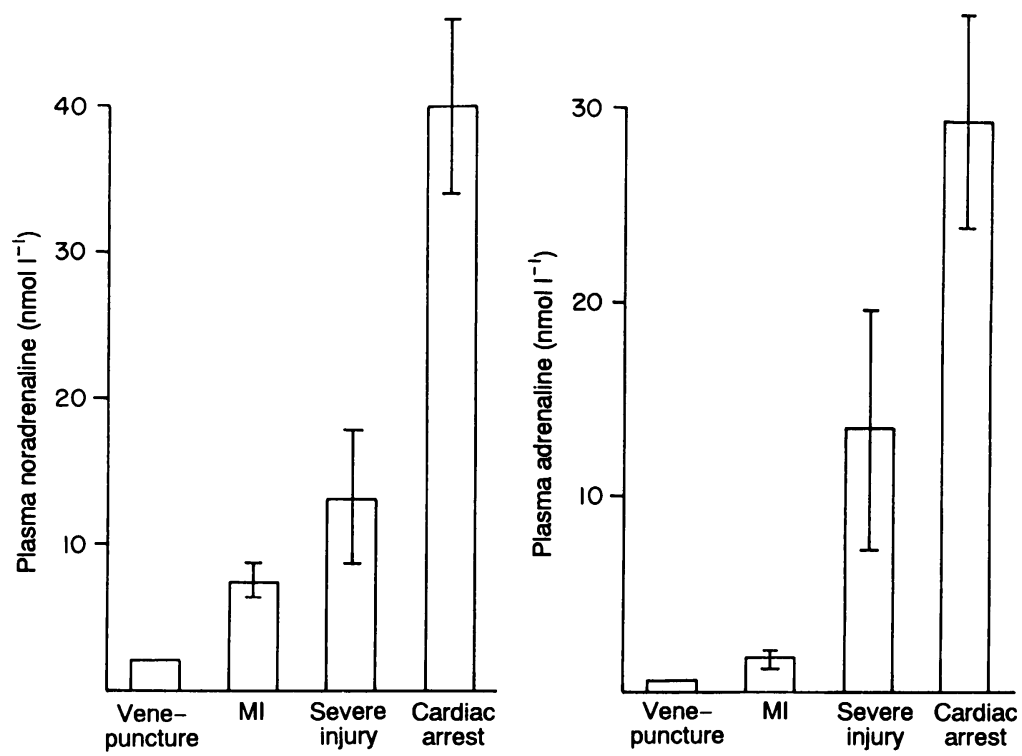

Fig. 1. Plasma adrenaline and noradrenaline responses in acute injury and illness (Fig. derived from Ref. 1.).

in asthmatics. It has been suggested that this may have pathophysiological sig? nificance in acute bronchospasm, or that it represents a phenomenon of 'adrenal exhaustion'.

\section{METHODS}

Twenty patients age 19-71 years (mean 45 years) presenting to an A\&E department with a history of reversible airway obstruction and an admission peak flow of $<65 \%$ of predicted value were studied over a 3-month period.

Prior to therapy an i.v. cannula was sited and a $5 \mathrm{ml}$ venous sample was drawn into a heparinized tube on ice. Plasma was separated and stored at $-80^{\circ} \mathrm{C}$ until analysis. Arterial blood gases were simultaneously sampled and pre- and posttreatment peak expiratory flow rates, pulse rate, respiratory rate and the degree of pulsus paradoxus were noted.

Plasma catecholamine concentrations were measured by a previously validated technique of high-performance liquid chromotography with electrochemical detection after preparation on cation exchange resin and alumina (Frayn \& Maycock, 1983). Patients were treated with high flow oxygen, $5 \mathrm{mg}$ nebulized salbutamol and $100 \mathrm{mg}$ intravenous hydrocortisone. Repeat nebulisers and additional therapy were given as clinically indicated. All patients were admitted and made an uncomplicated recovery. 


\section{RESULTS}

Most patients had low catecholamine levels despite clinically severe acute asthma adrenaline: median $0.41 \mathrm{nmoll}^{-1}$, range $0.05-14.6$, noradrenaline: median $3.2 \mathrm{nmoll}^{-1}$, range 0.9-27.4). Several, however, had markedly elevated levels, similar to those values seen in cardiac arrest (Fig. 1). These patients had the most clinically severe manifestations of asthma, i.e. impending respiratory arrest with silent chest, impaired consciousness and $\mathrm{CO}_{2}$ retention on arterial gas analysis.

As the results were not normally distributed (Fig. 2), a log conversion was required prior to simple linear regression analysis, to establish possible relationships between clinical and biochemical parameters of severity and catecholamine levels. Significant $\log$ relationships were established between adrenaline levels and $\mathrm{PaCO}_{2}$ $(R=0.646 P=0.002)$ (Fig. 3$)$, pulse rate $(R=0.588 P=0.006)$, percentage reduction in PEFR $(R=0.551 P=0.012)$ and pulsus paradoxus $(R=0.458 P=0.049)$. No significant relationships were observed between respiratory rate or $\mathrm{PaO}_{2}$ and log adrenaline. With regard to noradrenaline, two weak relationships were observed between $\log$ noradrenaline and $\mathrm{PaCO}_{2}(R=0.493 P=0.032)$ and pulsus paradoxus $(R=0.493 P=0.036)$. There were no significant relationships observed between log noradrenaline and pulse rate, percentage reduction in PEFR, respiratory rate or $\mathrm{PaO}_{2}$.

\section{DISCUSSION}

The small numbers in this study, particularly of patients with elevated catecholamine levels, mean that the statistical analyses should be interpreted with caution. However the observation that those patients with the most severe bronchoconstriction
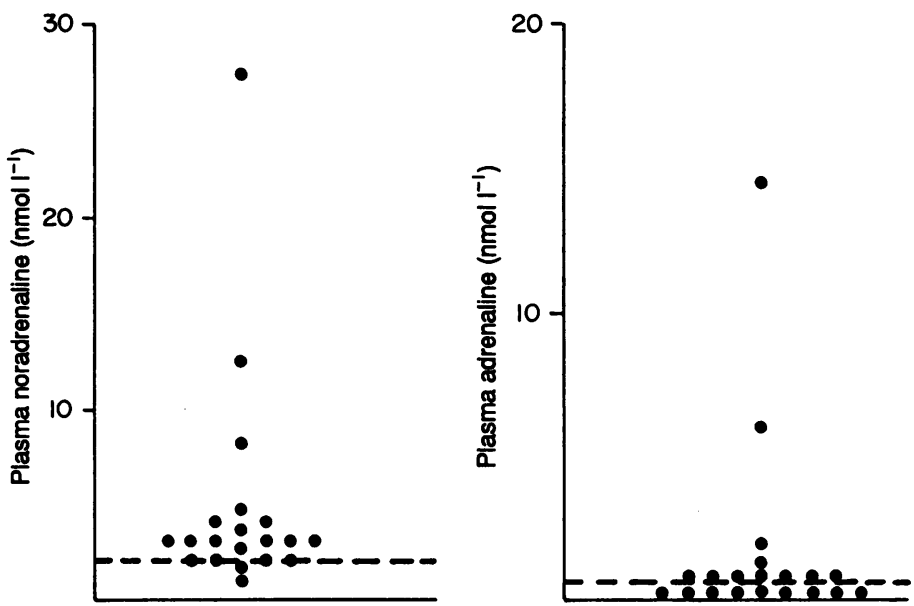

Fig. 2. Plasma adrenaline and noradrenaline levels in acute severe asthma. 


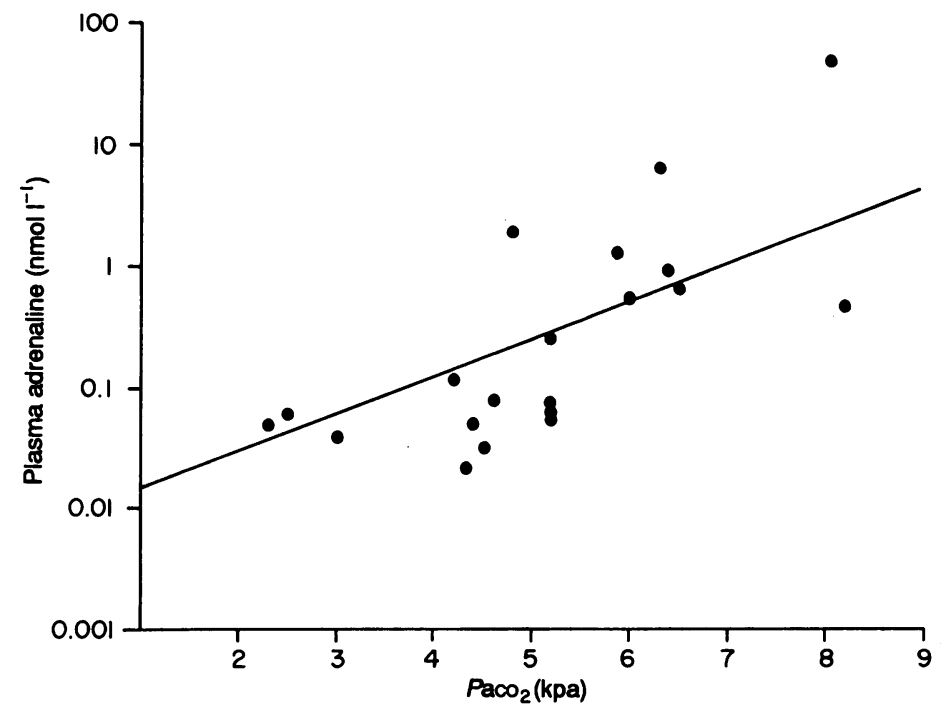

Fig. 3. Relationship between plasma adrenaline levels and arterial $\mathrm{PCO}_{2}$ levels.

and impending respiratory arrest had dramatically elevated catecholamine levels (up to those seen in cardiac arrest) has interesting implications. Certainly theseco patients were able to mount a large catecholamine response and did not therefore have adrenomedullary 'exhaustion'. Conversely the observation of the levels of catecholamines in the less severe patients seems to support suggestions of 'impaired' adrenomedullary responses in the face of physiological stresses such as hypoxia, increased pulmonary work and fear.

One possible explanation for this may be prior Beta agonist therapy by the patient or ambulance crew. Stimulation of Beta receptors has been shown to enhance catecholamine clearance from the circulation (Cryer, 1980) and this may account for the low levels observed in patients with less dramatic presentations, who are already perhaps partially treated.

Alternatively, it may not be 'abnormal' to have low catecholamine levels in acute bronchospasm until a critical stimulus is reached when a response is triggered. In other words, there may be nothing uniquely 'impaired' about the asthmatic's response to broncho-constriction compared to that of a non-asthmatic to the same event.

With regard to the nature of the stimulus for catecholamine release in the most severely affected patients, levels appear to be more closely related to the presence of hypercarbia rather than hypoxia. Obviously, it cannot be inferred that $\mathrm{CO}_{2}$ retention is the primary or sole trigger from this study, as plasma levels are also correlated with several clinical parameters of disease severity. However it is tempting to speculate that the development of respiratory acidosis provides the stimulus for the sympatho-adrenal response. $\mathrm{CO}_{2}$ rebreathing experiments in asthmatics and normal controls may indicate whether indeed hypercarbia acts as 
such a catecholamine stimulus and if there is a delayed or 'impaired' response in the former. Such considerations will form the basis for further research. Ultimately understanding the pattern of catecholamine release in acute severe asthma may have therapeutic applications with regard to both maintenance preventative therapy and emergency intervention.

\section{ACKNOWLEDGEMENT}

We would like to thank Mrs C. Sinclair for typing and preparing the manuscript.

\section{REFERENCES}

Carson K., Gronneberg R. \& Kjendahl P. (1985) Bronchodilation and inhibition of allergen induced bronchoconstriction by circulating epinephrine in asthmatic subjects. Journal of Allergy and Clinical Imminology 75, 586-593.

Cryer P. E. (1980) Physiology and pathophysiology of the human sympathoadrenal neuroendocrine system. In: H. L. Bleich \& M. J. Moore (Eds) Seminars in Medicine of Beth Israel Hospital Boston. New England Journal of Medicine 303, 436-444.

Frayn K. N. \& Maycock P. F. (1983) Sample preparation with ion-exchange resin before liquid chromatographic determination of plasma catecholamines. Clinical Chenistry 29, 1426-1428.

Ind P. W., Causon R. C., Brown M. J. \& Barnes P. J. (1985) Circulating catecholamines in acute asthma. British Medical Journal 290, 267-269.

Little R. A., Frayn K. N., Randall P. E., Stoner M. B. \& Maycock P. F. (1985) Plasma catacholamine concentrations in acute states of stress and trauma. Archives of Emergency Medicine 2, 46-47.

Warren J. B., Keynes R. J., Brown M. J., Jenner D. A. \& McNicol M. W. (1982) Blunted sympathoadrenal response to exercise in asthmatic subjects. British Journal of Diseases of the Chest 76, 147-149. 